\title{
TENDON HEALING INDUCED BY CHEMICALLY MODIFIED MRNAS
}

\author{
K. Groth ${ }^{1}$, T. Berezhanskyy ${ }^{1}$, M.K. Aneja ${ }^{1}$, J. Geiger ${ }^{1}$, M. Schweizer ${ }^{1}$, L. Maucksch ${ }^{1}$, T. Pasewald ${ }^{1}$, T. Brill ${ }^{1}$, \\ B. Tigani ${ }^{2}$, E. Weber ${ }^{2}$, C. Rudolph ${ }^{1, \beta}$ and G. Hasenpusch ${ }^{1, \S}$ \\ ${ }^{1}$ Ethris GmbH, 82152 Planegg, Germany \\ ${ }^{2}$ Novartis Institutes for Biomedical Research, 4056 Basel, Switzerland \\ $\S$ These authors contributed equally
}

\begin{abstract}
Tendon disorders are frequent both in human and veterinary medicine with high re-injury rates and unsatisfactory therapeutic treatments. Application of naked, chemicallymodified mRNA (cmRNA), encoding for therapeutic proteins, is an innovative approach to address tendon healing. In the current study, we demonstrated that injection of naked cmRNA, diluted in a glucose-containing solution, into tendons resulted in high protein expression in healthy and experimentally-injured tendons. Injection of bone morphogenetic protein 7 (BMP-7)-encoding cmRNA resulted in a significantly higher expression of BMP-7 protein and reduced formation of collagen type III, compared to vehicle control. Moreover, in a large animal model, reporter protein expression was detectable not only in healthy, but also in experimentally-injured, severely inflamed tendons. Summarising, these results demonstrated the potential of cmRNAs encoding for therapeutic proteins as a new class of drugs for the treatment of tendon disorders.
\end{abstract}

Keywords: mRNA, tendinopathy, tendon rupture, gene therapy, regenerative medicine, sheep.

*Address for correspondence:

PD Dr Carsten Rudolph

Ethris GmbH, Semmelweisstr. 3

82152 Planegg, Germany

Telephone number: +4989895578810

Fax number: +4989895578818

Email: rudolph@ethris.com

\section{Introduction}

Tendinopathies are common in animals and humans, especially in athletes (Kvist, 1994). For example, rotator cuff and common calcaneal tendons tendinopathies are frequently diagnosed among humans (Herrmann et al., 2014; Järvinen et al., 2005). Underlying medical reasons are multisided and predisposal factors, such as overloading due to training or joint malposition, age, gender, genetics, body weight or endocrinopathies, are similar in humans and animals (Baird et al., 2014; Ippolito et al., 1975; Magnan et al., 2014; Patterson-Kane and Rich, 2014; Perkins et al., 2005). In numerous cases, subclinical chronic damage, caused by overuse or degenerative processes, leads to an acute injury or even tendon rupture, accompanied by characteristic clinical symptoms (Järvinen et al., 1997). Besides degenerative processes, failed healing response and inflammation have also been proposed as causative agents for tendinopathies (Del Buono et al., 2011; Maffulli et al., 2010). Millar et al. (2015) demonstrated that, in human and experimentally injured tendons, elevated IL33 expression is a characteristic of early tendinopathy and identified miRNA29a as key regulator of IL-33 function and excessive collagen type III synthesis. Their data provide a molecular mechanism of microRNA-mediated integration of the early pathophysiologic events that facilitate tissue remodelling in human tendon after injury.

The natural healing potential of tendon tissue is low due to hypocellularity, hypovascularity and a low metabolic rate compared to other soft tissues (Bray et al., 1996; Liu et al., 2011; Sharma and Maffulli, 2005a). Therefore, the healing process is slow (James et al., 2008) and takes months or even years. Moreover, the healing process normally results only in tissue repair instead of regeneration and the original tensile strength and elasticity are usually not regained (Sharma and Maffulli, 2005b). As a consequence, recovery is rarely fully functional (Hogan et al., 2011; Sharma and Maffulli, 2005a) and the risk of re-injury or even tendon rupture is greatly increased (Mast, 1997).

Treatment methods can be categorised into conservative and surgical approaches. In cases of acute injury, besides rest and bandaging followed by controlled exercise, conservative therapy methods can also be intra-lesion application of various substances, such as corticosteroids (Hart, 2011; Muto et al., 2014), hyaluronic acid (Foland et al., 1992; Muneta et al., 2012) or glycosaminoglycans (Moraes et al., 2009). Furthermore, physical methods, such as electromagnetic stimulation or shockwave therapy (Bosch et al., 2010; Seeliger et al., 2014) are also used. Also, various approaches using stem cell-based (Martinello et al., 2013; Renzi et al., 2013; Smith, 2008) and growth factor-based therapies have been investigated (Arguelles et al., 2008; Shah et al., 2013; Witte et al., 2011).

The assumption that cytokines and growth factors play a key role during the healing process - namely that they stimulate cell proliferation as well as cell differentiation and formation of extracellular matrix components (Evans, 2014; Grotendorst, 1988; Molloy et al., 2003) - generated considerable interest in growth-factor based gene therapy. Various ex vivo and in vivo experiments provided promising results, such as improved tendon healing in a rat Achilles tendon model after bone morphogenic protein (BMP)-12 gene transfer (Majewski et al., 2008) or a positive influence 
of platelet-rich plasma on core lesions of superficial digital flexor tendon (SDFT) in horses (Bosch et al., 2010). In recent years, in the field of growth factor-based therapies, several studies have been focused on DNA gene transfer (Evans, 2014; Lou et al., 2001; Majewski et al., 2008; Nakamura et al., 1998). However, the results are still not highly efficient, due to limitations of nuclear entry in nondividing cells (Tong et al., 2009), and in addition gene transfer carries the potential risk of mutagenesis. On the other hand, messenger RNA has been successfully applied in several mouse models. Kormann et al. (2011) reported increased haematocrit levels after single intramuscular injection of modified murine erythropoietin-encoding mRNA. In addition, in a congenital mouse disease model of surfactant protein B deficiency, aerosol application of surfactant protein B-encoding mRNA reconditioned large parts of the lung. In the present study, we focused on application of chemically modified naked mRNA (cmRNA) in intact, as well as, surgically and chemically injured tendons.

\section{Materials and Methods}

All mRNAs used in the current study were produced by Ethris GmbH (Planegg, Germany), using proprietary SNIM $^{\circledR}$ RNA (Stabilised Non-Immunogenic mRNA) technology.

\section{Ex vivo transfection, cultivation and bioluminescence imaging}

Deep digital flexor tendons (DDFT), derived from horses, cattle, sheep or pigs, and common calcaneal tendons, derived from rats, were harvested within $1 \mathrm{~h}$ after animals were euthanised (horses, sheep and rats) or slaughtered (pigs and cattle) and rinsed twice in ice cold Dulbecco's phosphate-buffered saline (PBS) (Life Technologies GmbH, Darmstadt, Germany) containing $1 \%$ penicillin/streptomycin (PAA Laboratories $\mathrm{GmbH}$, Pasching, Austria). Modified naked mRNAs, encoding for luciferase (cmRNA $\left.{ }^{\text {LUC }}\right), \beta$-galactosidase (cmRNA ${ }^{\text {LacZ }}$ ) and human bone morphogenetic protein $7\left(\mathrm{cmRNA}^{\mathrm{hBMP}-7}\right)$, were diluted in different solvents and at different concentrations. Injection of cmRNA was performed in parallel to tendon fibre orientation using 23-G needles (Sterican, B. Braun Melsungen AG, Melsungen, Germany) and $1 \mathrm{~mL}$ Injekt $^{\circledR}-\mathrm{F}$ syringes (B. Braun Melsungen AG) for major tendons and $30-\mathrm{G}$ insulin syringes (BD Micro-Fine, Becton, Dickinson and Company, Franklin Lakes, NJ, USA) for rat tendons. cmRNA ${ }^{\mathrm{LUC}}$ was diluted in different solvents and prepared using commercially available solutions and standard laboratory chemicals (Table 1). HEPES-buffered glucose (HBG) (Sigma-Aldrich Chemicals, Schnelldorf, Germany) was adjusted to $\mathrm{pH} 7.4$ and prepared in four different concentrations, namely $2.5 \%, 3.75 \%, 5 \%$ and $10 \%$. cmRNA $^{\mathrm{LacZ}}$ and cmRNA ${ }^{\mathrm{BMP}-7}$ were prepared in saline solution only. Complexed cmRNA ${ }^{\mathrm{LUC}}$ was prepared using DreamFect ${ }^{\mathrm{FM}}$ Gold (OZ Biosciences, Marseille, France) as recommended by the manufacturer $(10 \mu \mathrm{g}$ cmRNA $^{\mathrm{LUC}} / 40 \mu \mathrm{L}^{\text {DreamFect }}{ }^{\mathrm{FM}}$ Gold) and using branched polyethyleneimine (brPEI) $25 \mathrm{kDa}$ (Sigma-Aldrich,
Schnelldorf, Germany) at an N/P ratio of 10 using $25 \mu \mathrm{g}$ cmRNA $^{\text {LUC }}$.

Ex vivo transfected tendons were incubated at $37{ }^{\circ} \mathrm{C}$ and $5 \% \mathrm{CO}_{2}$ in $50 \mathrm{~mL} \mathrm{DMEM}(1 \times)+$ GlutaMAX medium (Life Technologies, Darmstadt, Germany) containing $1 \%$ penicillin/streptomycin (PAA Laboratories $\mathrm{GmbH}$ ), $2 \%$ nystatin (Sigma-Aldrich Chemicals) and $10 \%$ FBS (Life Technologies).

Bioluminescence imaging (BLI) was conducted 1, 2 and $3 \mathrm{~d}$ after ex vivo transfection, using a Xenogen IVIS $^{\circledR}$ Spectrum in vivo imaging system (Caliper Life Sciences, Waltham, MA, USA). D-Luciferin substrate (S039, SYNCHEM, Felsberg/Altenburg, Germany), diluted in Dulbecco's PBS $(1 \times)$, was added to the cell culture flasks (100 $\mu \mathrm{g}$ D-Luciferin/mL medium) $1 \mathrm{~h}$ prior measurement of luciferase activity. Living Image ${ }^{\circledR} 2.50$ software (Caliper Life Sciences) was used for data analysis.

\section{Histological processing of ex vivo cultivated tendon explants}

$\beta$-galactosidase staining was performed $1 \mathrm{~d}$ after ex vivo transfection, according to Dai et al. (2003). Tendons were fixed on ice for $30 \mathrm{~min}$ in $0.5 \%$ glutaraldehyde (Carl Roth, Karlsruhe, Germany) and $2 \mathrm{mM}$ magnesium chloride hexahydrate (Carl Roth) in PBS and adjusted to $\mathrm{pH}$ 7.4. Subsequently, they were washed twice for $30 \mathrm{~min}$ at room temperature in rinsing buffer [100 mM HEPES, 5 mM DTT (Dithiotreitol, Sigma-Aldrich Chemicals), $1 \mathrm{mM} \mathrm{MgSO}$ (Magnesium sulphate heptahydrate, Carl Roth), $2 \%$ Triton X-100 (Carl Roth), pH 8.0] and then rinsed for $1 \mathrm{~h}$ at $50{ }^{\circ} \mathrm{C}$ in the same buffer. Next, tendons were incubated overnight in a non- $\mathrm{CO}_{2}$ incubator in X-Gal (5-bromo-4chloro-3-indolyl-D-galactoside) staining solution $[1 \mathrm{mg} /$ $\mathrm{mL}$ 5-Bromo-4-Chloro-3-indolyl $\beta$ (Sigma-Aldrich Chemicals), $2 \mathrm{mM} \mathrm{MgCl}, 5 \mathrm{mM} \mathrm{K} \mathrm{Fe}_{2}(\mathrm{CN})_{6}$ (Potassium ferricyanide (III), Carl Roth), $5 \mathrm{mM} \mathrm{K}_{4} \mathrm{Fe}(\mathrm{CN})_{6}$ (Potassium hexacyanoferrate(II) trihydrate, Carl Roth) in PBS pH 7.4]. Finally, tendons were fixed in $4 \%$ buffered formaldehyde solution (Roti Histofix, Carl Roth), dehydrated, embedded in paraffin and stained with haematoxylin and eosin.

For hBMP-7 immunohistochemistry (IHC), tendons were embedded in Tissue-Tek ${ }^{\circledR}$ O.C.T. ${ }^{\text {TM }}$ Compound (Sakura Finetek, Staufen, Germany), snap-frozen in liquid nitrogen and stored at $-80^{\circ} \mathrm{C}$. Cryosections were prepared and immunohistochemistry was performed by an external laboratory (Sophistolab AG, Muttenz, Switzerland) using a rabbit polyclonal hBMP-7 antibody (ab56023, abcam, Cambridge, UK) as primary antibody.

\section{In vivo studies in intact and injured rat common calcaneal tendons}

All experiments were approved by the local ethics committee for animal experiments and adhered to the international guidelines for the care and treatment of laboratory animals. Female Sprague Dawley rats (4 months of age, bodyweight 300-340 g, Janvier Labs, SaintBerthevin, France) were group-housed under a 12 h light/ dark cycle, with food and water ad libitum.

To determine luciferase reporter protein expression in intact rat common calcaneal tendons, animals were anaesthetised by isoflurane inhalation using air and $\mathrm{O}_{2}$ 
as carrier gases (3-5 vol \% isoflurane for induction in an inhalation chamber, followed by $1.5-2.5$ vol $\%$ for maintenance using an inhalation mask). Different doses of $\mathrm{cmRNA}^{\mathrm{LUC}}(0,10,20$ and $40 \mu \mathrm{g}$; dose volume $10 \mu \mathrm{L})$ were injected into the right common calcaneal tendon ( $n=4$ rats/dose group). At day 1, 2 and 7 post cmRNA ${ }^{\text {LUC }}$ injection, in vivo bioluminescence imaging was performed using PhotonIMAGER ${ }^{\mathrm{TM}}$ (Biospace Lab, Nesles-la-Vallée, France). BLI was conducted 15 min after that D-Luciferin substrate (L-8220, dissolved in saline; Biosynth, Staad, Switzerland) was administered intraperitoneally (150 mg/ $\mathrm{kg}, 5 \mathrm{~mL} / \mathrm{kg}$ ). Images were acquired using $10 \mathrm{~min}$ as integration time. No filter was used. Quantification was performed using a region of interest defined manually (common calcaneal tendon) and the results were expressed as total counts. M3Vision software (Biospace Lab) was used for data analysis. At day 7, rats were sacrificed using a $\mathrm{CO}_{2}$ chamber, tendons were explanted immediately and luciferase activity was measured again in tendon explants.

Therapeutic $\mathrm{cmRNA}^{\mathrm{hBMP}-7}$ was applied directly into injured, i.e. dissected and surgically repaired, common calcaneal tendons to investigate BMP-7 influence on early tendon healing. Prior to surgery, rats received a subcutaneous injection of $0.05 \mathrm{mg} / \mathrm{kg}$ of buprenorphine (Temgesic ${ }^{\circledR}$, Reckitt Benckiser, Wallisellen, Switzerland). Surgery was performed under inhalation anaesthesia, as described above. The left leg was prepared for aseptic surgery and then fixed into a custom-made holder to stabilise the ankle into a $90^{\circ}$ position, with the foot facing downwards. A skin incision was made along the longitudinal axis, on the plantar side of the right lower hind limb. Common calcaneal tendon was exposed and fully dissected along the transversal axis, in the mid-portion between the calcaneus and the insertion of the triceps surae muscle. An end-to-end anastomosis of the tendon stump was performed applying a three-loop pulley pattern suture using a non-absorbable monofilament (Prolene ${ }^{\circledR}$ 5-0, 3/8 reverse cutting needle P3, Ethicon, Johnson \& Johnson Medical, Norderstedt, Germany). Subsequently, either cmRNA $^{\text {hBMP-7 }}(100 \mu \mathrm{g})$ or vehicle were administered into the tendons, proximal and distal to the anastomosis, with a dose volume of $5 \mu \mathrm{L}$ per injection site $(30-\mathrm{G}$ insulin syringes, BD Micro-Fine). Next, the subcutaneous layer and the skin were closed by a continuous suture technique

Table 1. Solutions used for cmRNA dilution. A selection of primary ingredients is listed. ${ }^{1}$ commercially available,

${ }^{2}$ standard chemical solutions made in house, HEPES: 2-(4-(2-hydroxyethyl)-1-piperazinethansulfonic acid.

\begin{tabular}{|c|c|c|c|}
\hline Description & Label & Primary Ingredients & $\begin{array}{c}\text { Final concentration of ingredient in tested } \\
\text { vehicle solution }\end{array}$ \\
\hline \multirow{3}{*}{$\begin{array}{l}\text { Nitrogen } \\
\text { compound } \\
\text { containing }\end{array}$} & $\begin{array}{l}\text { Ammonium acetate } \\
\text { solution }^{1}\end{array}$ & Ammonium acetate & $3.8 \%$ \\
\hline & Aminosteril plus ${ }^{1}$ & $\begin{array}{l}\text { Total aminoacids } 100 \mathrm{~g} / \mathrm{L} \\
\mathrm{K}, \mathrm{Ca}, \mathrm{Mg}, \mathrm{Cl} \text {, phosphate, } \\
\text { acetate }\end{array}$ & $7.5 \%$ \\
\hline & Aminoven $15 \%{ }^{1}$ & Total aminoacids $150 \mathrm{~g} / \mathrm{L}$ & $11.25 \%$ \\
\hline \multirow{2}{*}{$\begin{array}{l}\text { Colloidal } \\
\text { solutions }\end{array}$} & HAES steril $10 \%{ }^{1}$ & $\begin{array}{l}\text { Hydroxyethyl starch } \\
100 \mathrm{~g} / \mathrm{L}, \mathrm{Na}, \mathrm{Cl}\end{array}$ & $7.5 \%$ \\
\hline & Gelafundin $4 \%^{1}$ & $\begin{array}{l}\text { Gelatine polysuccinate } \\
\quad 40 \mathrm{~g} / \mathrm{L}, \mathrm{Na}, \mathrm{C}\end{array}$ & $3 \%$ \\
\hline \multirow{4}{*}{$\begin{array}{l}\text { Glucose } \\
\text { containing }\end{array}$} & $\begin{array}{l}\text { HEPES buffered glucose } \\
2.5 \%^{2}\end{array}$ & $\begin{array}{c}12.5 \mathrm{mM} \text { HEPES, glucose } \\
25 \mathrm{~g} / \mathrm{L}\end{array}$ & $2.5 \%$ \\
\hline & $\begin{array}{l}\text { HEPES buffered glucose } \\
3.75 \%^{2}\end{array}$ & $\begin{array}{c}18.75 \mathrm{mM} \text { HEPES, glucose } \\
37.5 \mathrm{~g} / \mathrm{L}\end{array}$ & $3.75 \%$ \\
\hline & $\begin{array}{l}\text { HEPES buffered glucose } \\
5 \% \%^{2}\end{array}$ & $\begin{array}{l}25 \mathrm{mM} \text { HEPES, glucose } \\
50 \mathrm{~g} / \mathrm{L}\end{array}$ & $5 \%$ \\
\hline & $\begin{array}{l}\text { HEPES buffered glucose } \\
\qquad 10 \%^{2}\end{array}$ & $\begin{array}{l}50 \mathrm{mM} \text { HEPES, Glucose } \\
100 \mathrm{~g} / \mathrm{L}\end{array}$ & $10 \%$ \\
\hline \multirow{3}{*}{$\begin{array}{l}\text { Electrolyte } \\
\text { containing }\end{array}$} & Isotonic sodium chloride ${ }^{2}$ & Glucose, $\mathrm{Na}, \mathrm{Cl}$ & $0.9 \%$ \\
\hline & Ringer acetate $^{1}$ & $\mathrm{Na}, \mathrm{K}, \mathrm{Ca}, \mathrm{Mg}, \mathrm{Cl}$, acetate & $0.75 \%$ \\
\hline & Ringer lactate $^{1}$ & $\mathrm{Na}, \mathrm{K}, \mathrm{Ca}, \mathrm{Cl}$, lactate & $0.75 \%$ \\
\hline $\begin{array}{l}\text { Electrolyte } \\
\text { and glucose } \\
\text { containing }\end{array}$ & $\begin{array}{l}\text { Isotonic sodium chloride } \\
\text { containing } 5 \% \text { glucose }\end{array}$ & Glucose $50 \mathrm{~g} / \mathrm{L}, \mathrm{Na}, \mathrm{Cl}$ & $\begin{array}{l}0.9 \% \text { (saline }) \\
5 \% \text { (glucose })\end{array}$ \\
\hline
\end{tabular}


with an interrupted intra cutaneous suture using an absorbable synthetic thread (Safil ${ }^{\circledR}$ 6-0, B. Braun). Then, animals were allowed to wake up on a heating pad to aid the return to normal body temperature. Buprenorphine was administered every 8-12 h post-surgery for up to $2 \mathrm{~d}$.

At day 1, 2 and 7 post-surgery, $\mathrm{cmRNA}^{\text {hBMP-7}}$-treated and vehicle-treated rats were sacrificed with $\mathrm{CO}_{2}$ and the injured and contralateral intact common calcaneal tendons were explanted. Tendons were fixed overnight in $4 \%$ paraformaldehyde (Sigma-Aldrich Chemicals, Buchs, Switzerland), dehydrated with an ascending ethanol series and embedded in paraffin (Paraplast Xtra, Leica, Wetzlar, Germany). For immunohistochemistry, anti-BMP-7 antibody (ab56023, abcam), polyclonal anticollagen I antibody (ab 34710, abcam) and polyclonal anti-collagen III antibody (ab7778, abcam) were used as primary antibodies. Biotinylated goat anti-rabbit IgG (BA1000 , Vector Laboratories, Peterborough, UK) was used as secondary antibody. Staining was induced by peroxidase (biotin-labelled) activity. Sections were counterstained with haematoxylin (VWR International, Dietikon, Switzerland). In microscopy images, 3,3'-diaminobenzidine (DAB) staining was used as threshold and mean grey values of positive pixels were evaluated. Analysis was performed with Fiji/Image J Version 1.49k (National Institutes of Health, Bethesda, MD, USA; https://imagej.nih.gov/ij/).

\section{In vivo studies in an ovine model of acute tendon injury}

All experiments were approved by the local ethics committee for animal experiments and adhered to the international guidelines for the care and treatment of laboratory animals. Female mature 4-7 year old Merino sheepwere housed in groups under a $12 \mathrm{~h}$ light/dark cycle. Hay and water were provided ad libitum. No animals exhibited clinical or ultrasonographical evidence of tendon injury.

For tendon defect induction, a previously described collagenase-gel model was chosen (Smith, 2008; Watts et al., 2012). The metatarsal area of both hind limbs was clipped, shaved and aseptically prepared before either 500, 200 or 100 collagen digestion units (CDU) of collagenase type 1A (from Clostridium histolyticum; C0130, SigmaAldrich Chemicals) were injected into the DDFT of the left hind limb. Collagenase was diluted in Dulbecco's PBS $(1 \times)$, filter-sterilised and mixed with $50 \mu \mathrm{L}$ of thrombin solution (component 2, TISSUCOL Duo S Immuno, Baxter, Unterschleißheim, Germany). The injection was performed with a lateral approach in the mid-tarsal area under ultrasound guidance (Mindray DP 50 vet; Sonoring Schmitt-Haverkamp, Erlangen, Germany), using a 23-G needle and a DUPLOJECT System (Baxter). The collagenase-thrombin solution was combined with $50 \mu \mathrm{L}$ of fibrinogen solution (component 1, TISSUCOL Duo S Immuno, Baxter) during injection.

Antibiotic (Veracin-compositum $3 \mathrm{~mL} / 50 \mathrm{~kg}$; Albrecht, Aulendorf, Germany) was administered intramuscularly every second day for 5 consecutive days. $0.3 \mathrm{mg} / \mathrm{kg}$ body weight of buprenorphin-hydrochloride (Buprenovet ${ }^{\mathbb{R}}$ Multidose $0.3 \mathrm{mg} / \mathrm{mL}$; Bayer HealthCare, Leverkusen, Germany) were applied subcutaneously every $12 \mathrm{~h}$ for $2 \mathrm{~d}$;
$3 \mathrm{mg} / \mathrm{kg}$ body weight of ketoprofen (Romefen ${ }^{\circledR}$ PR $10 \%$; Merial, Hallbergmoos, Germany) were administered every $24 \mathrm{~h}$ for $5 \mathrm{~d}$, as analgesics. Ultrasound and daily clinical examination were performed using a portable Mindray DP50 vet ultrasound machine (Sonoring Schmitt-Haverkamp) with a linear probe (5-12 MHz). Diameter of the DDFT was measured in the mid-tarsal area, $2 \mathrm{~cm}$ below the applied suture. In group treated with $100 \mathrm{CDU}$, external thickness was measured from medial to lateral in the same mid-tarsal area by using a digital caliper.

$6 \mathrm{~d}$ after collagenase-gel injection, cmRNA ${ }^{\mathrm{LuC}}$, diluted in $5 \% \mathrm{HBG}$, was injected into healthy and damaged DDFT of both hind limbs. Procedure was performed under general anaesthesia. Test item ( $\left.\mathrm{cmRNA}^{\mathrm{LUC}}\right)$ was injected in two separate injections of $150 \mu \mathrm{g}=300 \mu \mathrm{g}$ in total (500 CDU group, $n=2), 200 \mu \mathrm{g}=400 \mu \mathrm{g}$ in total (200 CDU group, $n=2)$ and $250 \mu \mathrm{g}=500 \mu \mathrm{g}$ in total (100 CDU group, $n=2)$, under ultrasound guidance (proximal and distal area of the defect). At the end of the injection, some air was drawn into the syringe and injected to ensure that syringe and needle were completely emptied. During anaesthesia, ketoprofen $3 \mathrm{mg} / \mathrm{kg}$ (Romefen ${ }^{\circledR}$ PR $10 \%$; Merial) was administered intravenously.

On the next day, sheep were euthanised by intravenous overdose of pentobarbital (Euthadorm ${ }^{\circledR}$; CP-Pharma, Burgdorf, Germany). Subsequently, tendons were harvested and immediately incubated for $1 \mathrm{~h}$ in D-Luciferin solution (100 $\mu \mathrm{g}$ D-Luciferin/mL PBS) at $37{ }^{\circ} \mathrm{C}$ and $5 \% \mathrm{CO}_{2}$. BLI was performed using Xenogen IVIS $^{\circledR}$ Spectrum in vivo imaging system (Caliper Life Science). Measurement was operated in the field of view A with high sensitivity (binning 16) and an exposure time of $1 \mathrm{~min}$. Living Image ${ }^{\circledR} 2.50$ software (Caliper Life Sciences) was used for the analysis. Tendons were fixed for $24 \mathrm{~h}$ in $4 \%$ paraformaldehyde, dehydrated with an ascending ethanol series and embedded in paraffin. In intact tendons, five

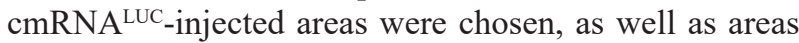
$3 \mathrm{~cm}$ proximal and distal to the injection site. In injured tendons, central and peripheral areas of the defect were selected and $3 \mu \mathrm{m}$ thick sections were stained with haematoxylin and eosin for histopathological examination.

Blood was taken at day 0, day 6 (before mRNA application) and day 7 (before euthanasia) and full blood count as well as liver and kidney test values were analysed by an external veterinary laboratory.

\section{Statistical analysis}

All statistical analyses were performed with GraphPad Prism 5. Results were presented as mean \pm standard deviation (SD), with $n$ equal to the number of samples per group. Differences between groups were analysed for statistical significance with significance attained at $p<0.05$ using one-way ANOVA.

\section{Results}

\section{Injection of naked cmRNA resulted in high protein expression in tendon explants}

Naked cmRNA encoding for firefly luciferase (FFL) was dissolved in saline and injected into freshly explanted 
tendons. Subsequently, injected explants were incubated and luciferase activity was measured $24 \mathrm{~h}$ later by BLI. Expression of luciferase was detected in specimen injected with cmRNA ${ }^{\mathrm{LUC}}$, but not in untreated control tendons or in tendons injected with saline solution only. Based on these promising findings, further experiments were conducted on explants of different animal species to investigate whether the concept of ex vivo transfection could be successfully applied to more mammals. Interestingly, besides expression in porcine tendon explants, injection of naked cmRNA ${ }^{\mathrm{LUC}}$ resulted in distinct luciferase expression in explanted tendons of sheep, cattle, horses and rats (Fig. 1A). Notably, expression patterns revealed a particular distribution, with higher luciferase activity at the injection site and a slim, tube-like distribution within the entire explant.

In a next set of experiments, we used explanted tendons from cattle (Fig. 1B), pigs and sheep (data not shown) to examine the dose-dependency of the reporter protein activity. As expected, transfection efficacy directly correlated with the amount of the injected test item (cmRNA ${ }^{\mathrm{LUC}}$ ) (Fig. 1B). To identify the transfected cells, cmRNA coding for the bacterial enzyme $\beta$-galactosidase was injected into porcine (Fig. 1C,D) and sheep (data not shown) tendon explants. Already after $1 \mathrm{~d}$ of ex vivo incubation, expression of $\beta$-galactosidase was detectable macroscopically by visual inspection. Microscopic analysis
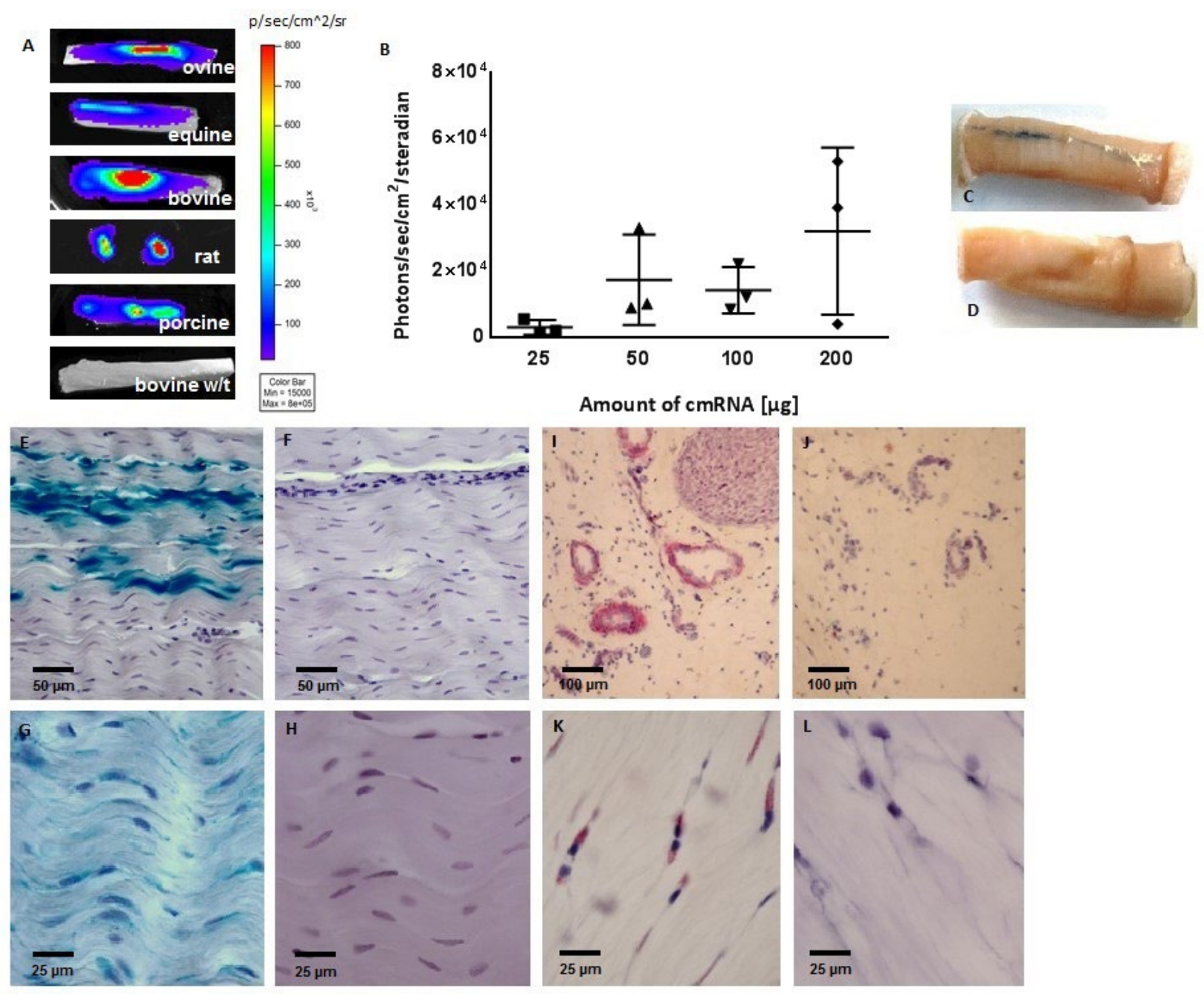

Fig. 1. Protein expression in intact tendon explants after naked cmRNA injection. (A) Bioluminescence imaging (BLI) $24 \mathrm{~h}$ after cmRNA ${ }^{\mathrm{LUC}}$ injection in tendon explants of different species. Either $26.6 \mu \mathrm{g}[0.65 \mathrm{mg} / \mathrm{mL}]$ (rat), $50 \mu \mathrm{g}[0.5 \mathrm{mg} / \mathrm{mL}]$ (bovine, equine) or $100 \mu \mathrm{g}[1 \mathrm{mg} / \mathrm{mL}]$ (porcine, ovine) of naked cmRNA ${ }^{\mathrm{LUC}}$ were injected. Expression of luciferase was detected in all species tested. (B) Luciferase expression was dose-dependent. Bovine tendon explants were injected with either $25 \mu \mathrm{g}, 50 \mu \mathrm{g}, 100 \mu \mathrm{g}$ or $200 \mu \mathrm{g}$ of cmRNA $\mathrm{cmC}^{\mathrm{LUC}} 250 \mu \mathrm{L}$ of isotonic saline solution $(\mathrm{NaCl})$. Mean expression $\pm \mathrm{SD}$ of $24 \mathrm{~h}$ time point is shown $(n=3)$. (C) $24 \mathrm{~h}$ after cmRNA $^{\text {LacZ }}$ transfection, tendon explants showed macroscopically visible blue staining (indicating activity of $\beta$-galactosidase). (D) In contrast, no activity of $\beta$-galactosidase was found in control explants transfected with cmRNA $^{\text {LUC }}$. (E, G) Sections of LacZ stained tendon explants transfected with cmRNA ${ }^{\mathrm{LacZ}}$ and $(\mathbf{F}, \mathbf{H}) \mathrm{cmRNA}^{\mathrm{LUC}}$. (I,K) Immunostaining for hBMP-7, in sections of cmRNA ${ }^{\text {hBMP-7 }}$ transfected rat common calcaneal tendons, showed red staining (indicating evidence of hBMP-7) in (I) vascular walls and connective tissue and (K) tenocytes. (J,L) Controls transfected with cmRNA ${ }^{\text {LUC }}$ did not show remarkable evidence of hBMP-7. 
A

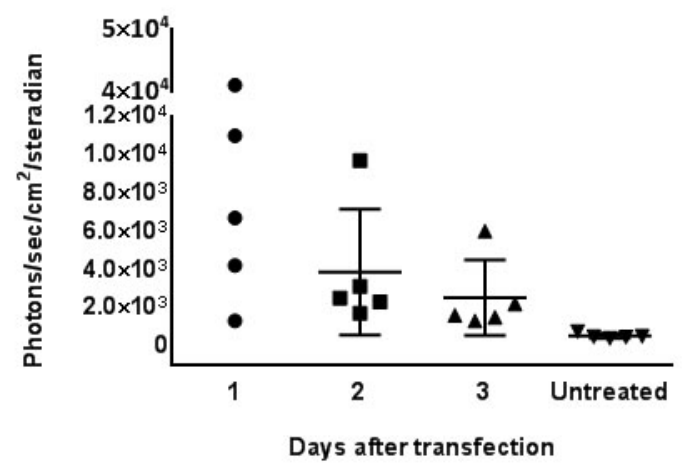

C

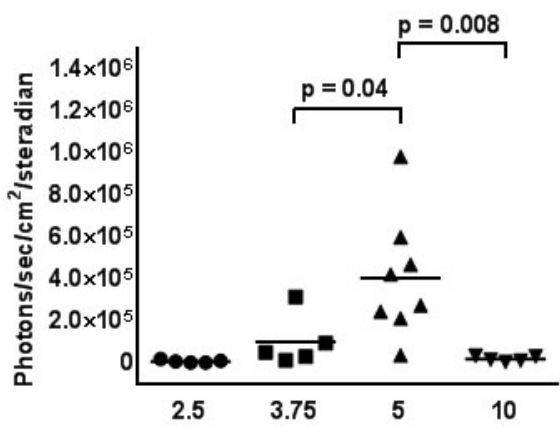

HBG concentration in percent
B

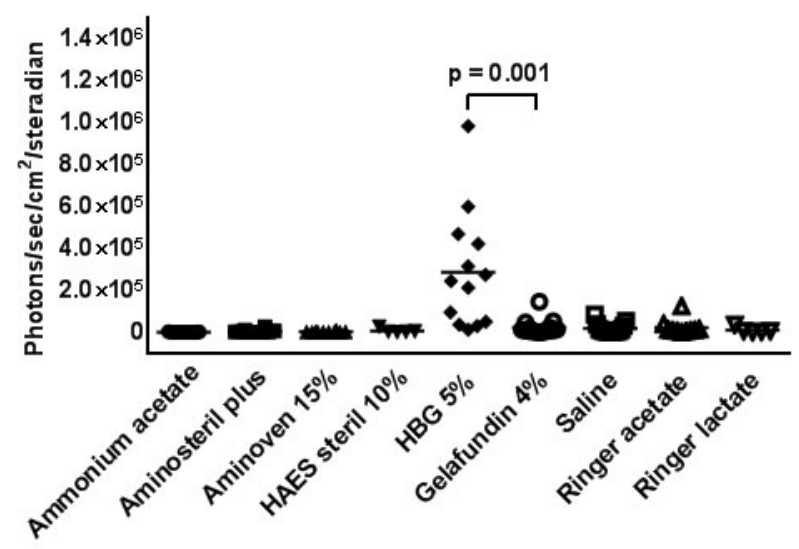

D

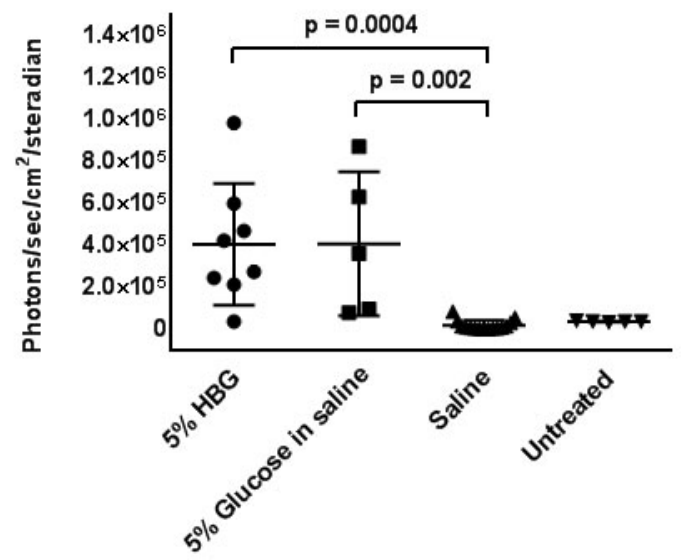

E

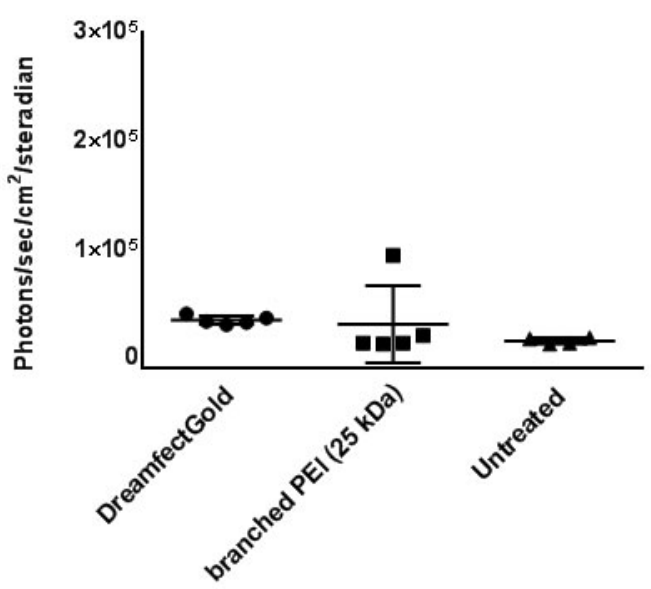

Fig. 2. Expression kinetics and comparison of different solvents used for naked cmRNA injection. (A) Expression kinetic of luciferase was evaluated in bovine tendon explants after transfection with $50 \mu \mathrm{g}$ cmRNA ${ }^{\mathrm{LUC}}$ [0.5 mg/ $\mathrm{mL}]$ dissolved in saline. (B) $50 \mu \mathrm{g} \mathrm{cmRNA} \mathrm{cUC}^{\mathrm{LUC}}[0.25 \mathrm{mg} / \mathrm{mL}]$ were diluted in different solvents and injected into bovine tendon explants $(n \geq 5)$. Activity of luciferase was measured $1 \mathrm{~d}$ after ex vivo transfection revealing maximum expression upon use of HEPES-buffered glucose (HBG $5 \%$ ) as solvent. (C) Comparison of different HBG concentrations showed that maximum luciferase expression levels were reached using $5 \% \mathrm{HBG}$ as solvent. However, higher or lower concentrations of HBG resulted in statistically significant lower expression levels. (D) Comparison of glucose-containing saline and HEPES-buffered solution (HBG $5 \%$ ). (E) cmRNA ${ }^{\text {LUC }}$ complexed using DreamFect ${ }^{\mathrm{FM}}$ Gold and branched Polyethylenimine carrier system. 
showed strong $\beta$-galactosidase positivity (indicated by a blueish nuclear staining) in tenocytes and fibroblasts close to the site of injection and within the collagen fibre bundles (Fig. 1E,G). No $\beta$-galactosidase positive cells were found in control tendons injected with cmRNA coding for FFL (Fig. 1F,H).

Encouraging results with reporter genes (luciferase and $\beta$-galactosidase) prompted us to investigate the applicability of this technology to produce therapeutic proteins. BMP-7 was selected as a therapeutic target, due to its ability to increase healing processes by stimulating effects on tenocytes. Proof of concept experiments in rats aimed to evaluate the pharmacologic efficacy of human BMP-7 cmRNA. Moreover, using human BMP-7 cmRNA allowed us to quantify hBMP-7 protein, resulting from BMP-7 cmRNA, without significant cross-reactivity with the endogenous BMP-7. For these reasons, human BMP-7 was chosen for further ex vivo and in vivo studies. As further in vivo experiments were intended to be conducted in rats, cmRNA $^{\text {hBMP-7 }}$ was injected into rat common calcaneal tendons. IHC for hBMP-7 was performed after $1 \mathrm{~d}$ of cultivation. Using this methodology, hBMP-7 positive signals were found in vascular walls and connective tissue (fibroblasts and tenocytes) of cmRNA ${ }^{\mathrm{hBMP}-7}$-injected tendon specimens (Fig. 1I,K). Also control tendons were slightly positive, but only in vascular walls (Fig. 1J,L).

\section{Vehicle composition strongly impacted transfection efficacy in tendon explants}

Further experiments were carried out in bovine tendons, due to their easy accessibility from the local slaughterhouse. After establishing the expression dose-dependency (Fig. 1B), the subsequent study was initiated to explore the expression kinetics of $\mathrm{cmRNA}^{\mathrm{LUC}}$ ex vivo. Results in bovine tendons showed a peak of expression $1 \mathrm{~d}$ after injection and a subsequent 2-fold decline over the next $2 \mathrm{~d}$. $3 \mathrm{~d}$ after transfection, luciferase expression was reduced to background levels (Fig. 2A).

Hypothesising that electrolytes, sugars or amino acids might influence transfection efficacy, we investigated different commercially available and standard laboratory solutions as vehicles for cmRNA. We hypothesised that (1) osmotic gradients may increase intracellular electrolyte influx and thereby intracellular uptake of cmRNA, (2) providing cells with additional amino acids may enhance the translation of cmRNA, (3) precipitating the mRNA with ammonium acetate may result in a depot effect, thereby enabling extended expression. Furthermore, colloidal solutions were used to test the influence of large molecules on transfection of tendon tissue. As highest expression levels were observed $24 \mathrm{~h}$ after cmRNA ${ }^{\mathrm{LUC}}$ injection, this time point was selected for the comparison of different solvents.

Our results revealed a strong influence of the used solvent/electrolyte on the resulting luciferase expression. This effect was most prominent when comparing electrolyte and/or glucose-containing solutions with solutions containing amino acids (Fig. 2B). Noticeably, glucose-containing solution, such as HEPES buffer containing $5 \%$ glucose (HBG $5 \%$ ), resulted in higher luciferase expression compared to saline $(p<0.001)$ or amino acids-containing solution (57-fold compared to Aminosteril plus; Fresenius Kabi Deutschland $\mathrm{GmbH}$, Bad Homburg, Germany). No luciferase expression was detected for cmRNA ${ }^{\text {LUC }}$ in ammonium acetate solution. Reasoning, whether concentration of glucose influenced transfection efficacy, we observed the highest luciferase expression at a glucose concentration of $5 \%$, which decreased several folds when glucose concentration was either increased (20-fold less) or decreased (50-fold) (Fig. 2C). To verify that these findings were transferable to other species, similar results were obtained in tendons derived from pigs and horses (data not shown).

Cationic lipids and polymers are commonly used carrier systems for facilitating cell membrane penetration and thereby enhancing transfection efficacy of nucleic acids in vitro and in vivo. Hence, the two standard transfection reagents, DreamFect ${ }^{\mathrm{FM}}$ Gold (lipid based) and branched polyethylenimine (polymer based), were tested, assuming that these carriers would result in increased transfection levels. Surprisingly, both carriers did not result in any detectable luciferase activity, thereby confirming lack of transfection (Fig. 2E).

\section{Naked chemically-modified mRNA transfected intact rat common calcaneal tendons in vivo}

cmRNA $^{\text {LUC }}$, dissolved under optimised vehicle conditions (HBG containing $5 \%$ glucose, adjusted to $\mathrm{pH} 7.4$ ), was injected into the common calcaneal tendon of rats at 3 different doses $(40,20$ and $10 \mu \mathrm{g}$, i.e. $0.2,0.1$ and $0.05 \mathrm{mg} / \mathrm{kg}$ body weight) to explore whether our findings from ex vivo studies were translatable in vivo. Vehicle (HBG containing $5 \%$ glucose, adjusted to $\mathrm{pH}$ 7.4) was injected as negative control. Expression of luciferase was measured using BLI 1, 2 and $7 \mathrm{~d}$ after injection of the test item (Fig. 3A). A dose-dependent luciferase expression and expression kinetics similar to our results in ex vivo studies using tendon explants were observed (Fig. 3A,B). Peak expression was observed $1 \mathrm{~d}$ after transfection, which declined to background levels within $7 \mathrm{~d}$ (Fig. 3B).

\section{Naked cmRNA ${ }^{\text {hBMP-7 }}$ positively affected early healing in injured rat common calcaneal tendons in vivo}

The capability to overexpress a potential therapeutic protein using cmRNA was investigated in a rat model of acute tendon rupture. The common calcaneal tendon was surgically dissected and cmRNA coding for hBMP7 ( cmRNA $^{\text {hBMP-7 }}$ ) was injected into both ends of the stumps. Subsequently, dissected stumps were re-adapted using surgical sutures and the animals recovered from anaesthesia. Content of BMP-7, collagen type I and III was measured 1, 2 and $7 \mathrm{~d}$ after surgery by IHC.

Higher levels of hBMP-7 in tendons of cmRNA ${ }^{\text {hBMP- }}$ 7-treated animals could be measured at all time points, compared to vehicle treated animals (Fig. 3C). A statistically significant difference $(p=0.03)$ was observed $2 \mathrm{~d}$ after the application of the test item.

No difference was found at any of the examined time points between vehicle and cmRNA ${ }^{\text {hBMP-7 }}$-treated animals with respect to the content of collagen type I (Fig. 3E). However, significantly ( $p=0.03$ ) lower levels of collagen type III were found $7 \mathrm{~d}$ after tenotomy and injection 

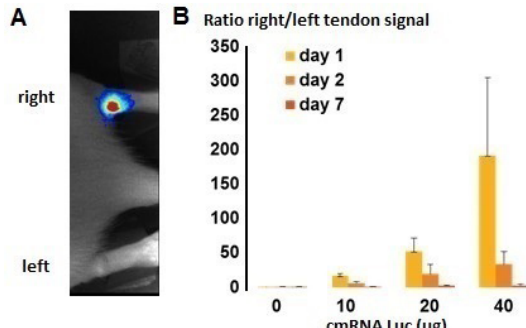

D
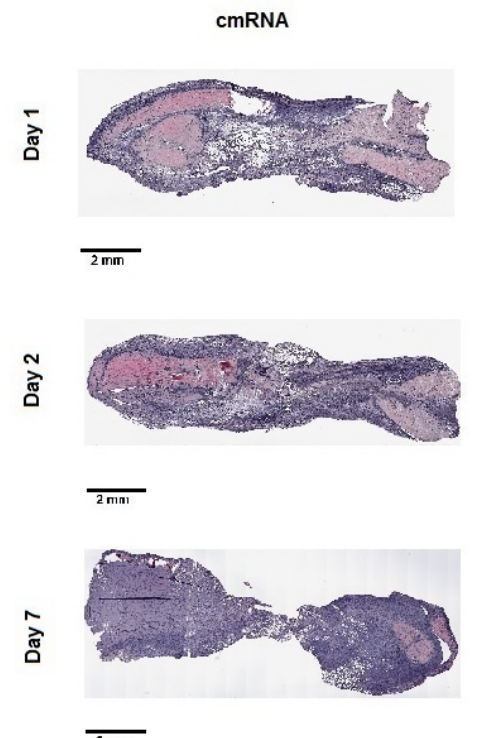
$\overline{2 \mathrm{~mm}}$

\section{$c$}
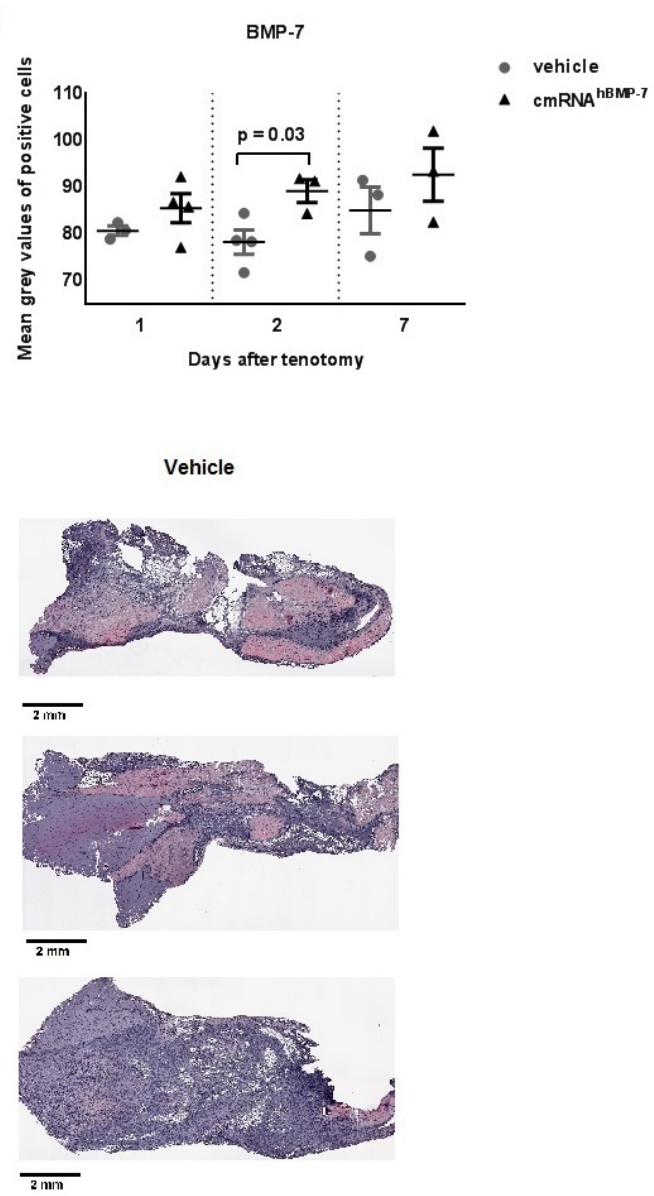

E

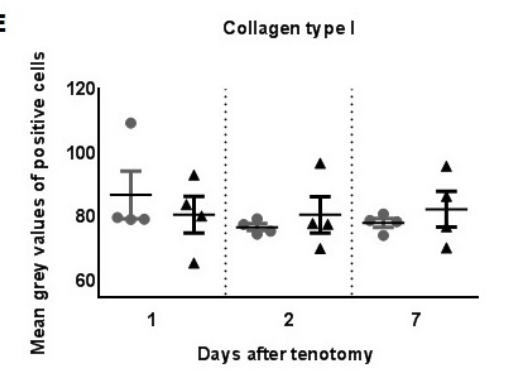

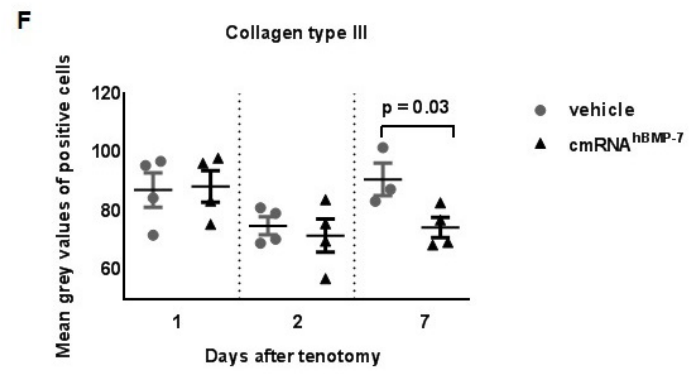

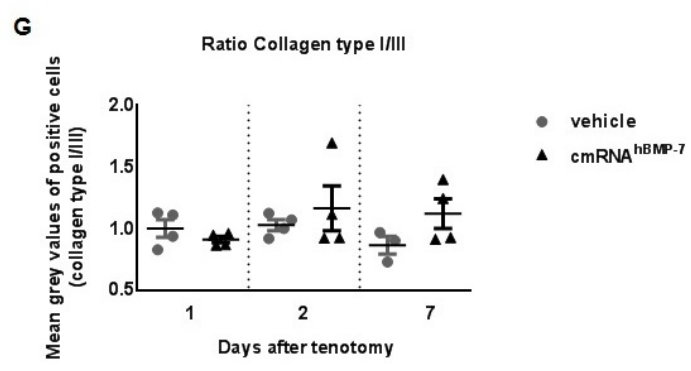

Fig. 3. Protein expression in intact and injured rat common calcaneal tendons upon injection of cmRNA in vivo. (A) In vivo luciferase activity was measured 1, 2 and $7 \mathrm{~d}$ after injection of 3 different doses of cmRNA ${ }^{\text {LUC }}$ into the common calcaneal tendon of rats ( $n=4$ per doses group). (B) Results revealed dose-dependent expression of luciferase with a maximum $1 \mathrm{~d}$ after test item application and declining expression up to $7 \mathrm{~d}$ post injection. (C) Immunostaining for hBMP-7 upon injection of cmRNA $\mathrm{cBMP}^{\mathrm{hB}}$ into injured common calcaneal tendons of rats. (D) Histopathological examination of common calcaneal tendons treated with cmRNA or vehicle. (E) At any time point examined, immunostaining revealed no difference between the levels of collagen type I, upon treatment with cmRNA $^{\text {hBMP-7 }}$, compared to vehicle. (F) Levels of collagen type III at day 1, 2 and 7 post treatments. (G) Ratios of collagen type I to collagen type III immunostaining showed no significant difference between cmRNA $^{\text {hBMP-7 }}$ and vehicle treated animals, at any time point examined. 
of cmRNA ${ }^{\text {hBMP-7 }}$ (Fig. 3F). The ratio between collagen type I and III showed no significant difference between cmRNA $^{\text {hBMP-7 }}$ and vehicle-treated animals, at any time point examined (Fig. 3G).

At day 1 and 2 post-surgery, histopathological examination of the injured common calcaneal tendon revealed an inflammatory reaction with migration of granulocytes and necrotic areas with haematoma in both groups. $7 \mathrm{~d}$ post-surgery, further proliferative progress was apparent in both groups (Fig. 3D).

\section{Naked cmRNA efficiently transfected injured and intact tendons in large animals}

Matrix disorganisation, fibre disorientation, hypercellularity and vascular ingrowth are characteristic histopathological findings during acute tendinopathy. As surgically injured rat tendons did not resemble these conditions, we additionally investigated cmRNA transfection efficacy in a large animal model of acute tendinopathy. Collagenase has already been used to generate tendon defects in sheep (Martinello et al., 2013). However, those defects do not closely resemble the morphology of acute tendon defects as seen in the clinics, as resulting inflammation and tissue destruction are distributed over the entire tendon. In contrast to this, clinical acute tendonitis is characterised by focal areas with loss of tissue structure, necrosis, inflammation and hematoma. Recently, Watts et al. (2012) described that injection of collagenase diluted in a fibrin and thrombin solution into superficial digital flexor tendons (SDFT) more closely resembled the clinical picture of acute tendinopathy in horses. We adapted this concept for establishing a sheep model of similar acute focal tendon defects. Therefore, under ultrasound guidance, collagenase diluted in fibrin and thrombin was injected with three different doses (100, 200 and 500 CDU) into the DDFT of anaesthetised sheep. Echography performed before, 3 and $5 \mathrm{~d}$ after collagenase-gel injection, showed clear inhomogeneity in all groups as early as $3 \mathrm{~d}$ after injection (Fig. 4A-F).
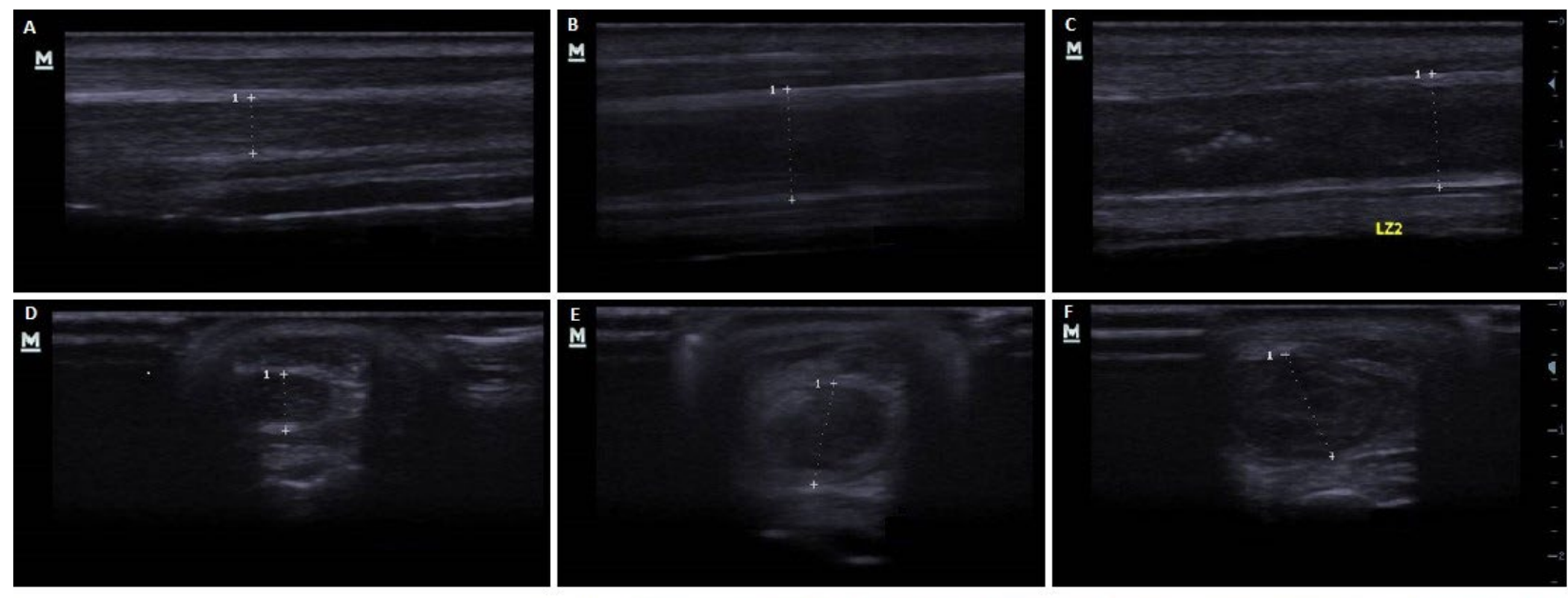

G
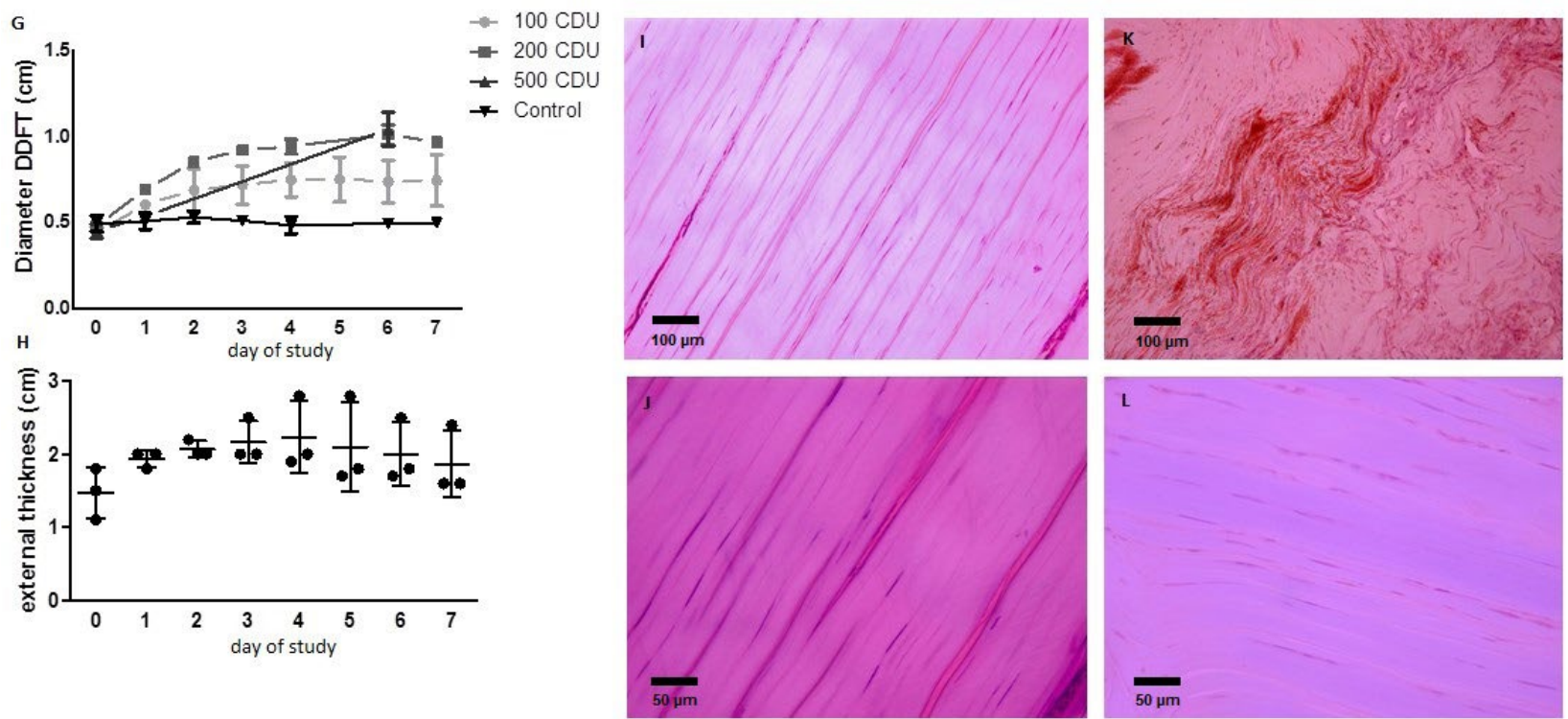

Fig. 4. Pathology of collagenase-gel-induced tendon defects in sheep. (A-C) Longitudinal (D-F) and transversal ultrasound images of a sheep's injured hind limb. Longitudinal and transversal ultrasound image at (A,D) day 0 before collagenase injection, $(\mathbf{B}, \mathbf{E}) 3$ and $(\mathbf{C}, \mathbf{F}) 7 \mathrm{~d}$ after collagenase-gel injection (100 CDU). (G) Diameter analysis during experimental period of tendons injected with either 100, 200 or $500 \mathrm{CDU}$ and untreated contralateral controls. Data are presented as mean $\pm \mathrm{SD}(n=2)$. (H) External thickness analysis of sheep treated with $100 \mathrm{CDU}$ during experimental period. Data are shown as mean $\pm \mathrm{SD}(n=2)$. Histopathological examination of $(\mathbf{I}, \mathbf{J})$ intact and $(\mathbf{K}, \mathbf{L})$ injured sheep tendons. 
Moreover, a dose-dependent increase of DDFT diameter (Fig. 4G) and limbs external thickness (1.5-fold within 4 d) was observed. DDFT diameter remained increased, whereas external thickness decreased back to untreated levels within $7 \mathrm{~d}$ (Fig. $4 \mathbf{H}$ ).

Pathological examination of tendons showed macroscopically visible haematomas in up to one third of the entire tendon, upon the injection of $500 \mathrm{CDU}$ of collagenase-gel and haematomas in up to one quarter of the entire tendon, upon the injection of $200 \mathrm{CDU}$ of collagenase-gel. No haematoma was visible upon a dosage of $100 \mathrm{CDU}$ of collagenase-gel. For all tested doses, histological examination revealed conglomerates of red blood cells, granulocytes, necrosis and loss of fibre structure in the central area of all defects (Fig. 4K). In the periphery of the defects, adjacent fibres were swollen, connections between fibres were loosened and cell density was increased (Fig. 4L) compared to intact tendons (Fig. $4 J)$.

cmRNA $^{\text {LUC }}$ in $5 \%$ HBG-containing buffer was injected with 3 different doses $(300,400$ and $500 \mu \mathrm{g})$ into healthy and injured tendons (defects generated using 500, 200 and
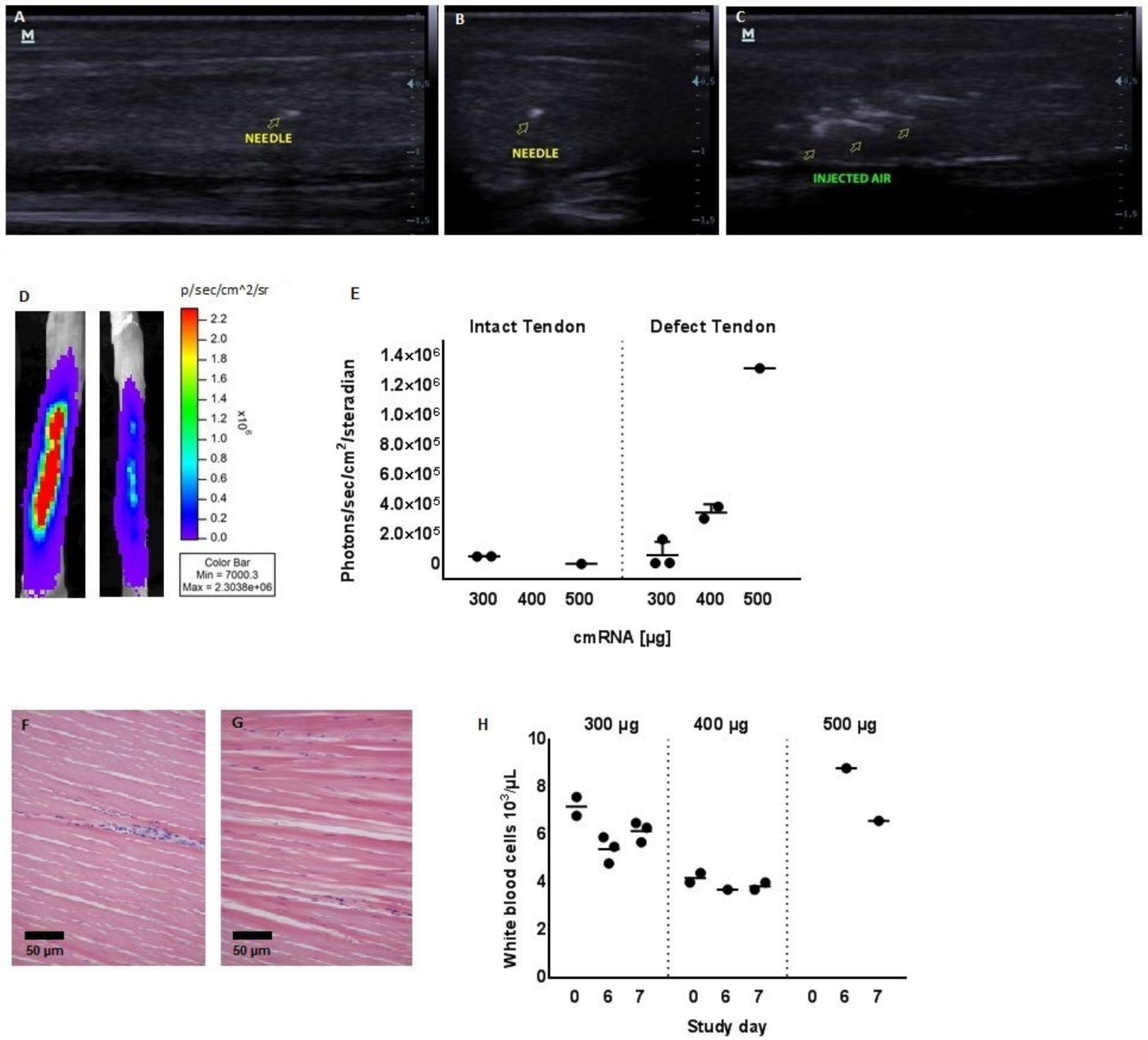

Day 0: before application of Collagenase-gel Day 6: before application of $\mathrm{cmRNA}$

Day 7: 24 hours after application of cmRNA

Fig. 5. Transfection of injured and intact tendons in sheep. (A) Longitudinal and (B) transversal ultrasound image of a damaged DDFT at day 6, with needle inserted in the central part of the tendon. (C) Longitudinal ultrasound image immediately after cmRNA ${ }^{\mathrm{LUC}}$ injection. Injected air was visible in the central area of the tendon. (D) Exemplary ex vivo BLI of damaged (left) and intact (right) explanted contralateral ovine DDFT $24 \mathrm{~h}$ after in vivo injection of $400 \mu \mathrm{g}$ of $\mathrm{cmRNA}^{\mathrm{LUC}}$ in each DDFT. (E) Ex vivo luciferase activity $24 \mathrm{~h}$ after injection of increasing amounts of $\mathrm{cmRNA}^{\mathrm{LUC}}$. Each dot represented measured luciferase values in one individual animal. $(\mathbf{F}, \mathbf{G})$ Haematoxylin-eosin staining of intact $\mathrm{cmRNA}^{\mathrm{LUC}}$-treated tendon at $(\mathbf{F})$ the injection site and $(\mathbf{G}) 3 \mathrm{~cm}$ proximal to the injection site. Original magnification 20×. (H) Analysis of white blood cell (WBC) from blood taken at day 0 , day 6 and day 7. 
$100 \mathrm{CDU}$ of collagenase-gel), under ultrasound guidance (Fig. 5A,B). Air was withdrawn in the syringe, together with the test item, to visualise the application (Fig. 5C). Luciferase expression was measured ex vivo $24 \mathrm{~h}$ after application, revealing luciferase activity in both, intact and injured tendons. Results showed no dose-dependent increase of luciferase expression in healthy tendons. On the contrary, increasing amounts of cmRNA ${ }^{\mathrm{LUC}}$ led to increased luciferase expression (Fig. 5D,E).

Histopathological examination of $\mathrm{cmRNA}^{\mathrm{LUC}}$-treated intact tendons revealed predominantly intact tendon tissue without pathological findings, except mild cellular infiltrates of macrophages and granulocytes (Fig. 5F). Tissue distal and proximal to the injection site was without any abnormalities (Fig. 5G).

Blood was taken when the collagenase-gel injection was performed, before that cmRNA ${ }^{\mathrm{LUC}}$ was injected and $24 \mathrm{~h}$ later, before the animals were euthanised. Haematology (white blood cell count, haematocrit, platelet count and red blood cell count) revealed no clinically significant abnormalities during the entire study in any of the experimental groups (Fig. 5H). Also, clinical chemistry (creatinine, blood urea nitrogen, aspartate aminotransferase, alanine aminotransferase, acute phosphatase, glutamate dehydrogenase) did not exhibit any clinically significant deviations at any of the time point examined. Moreover, also serum cytokines (interleukin-6, tumour necrosis factor $\alpha$, interferon $\alpha$ and $\gamma$ ) did not show any relevant increase during the entire study (data not shown).

\section{Discussion}

For the treatment of various pathological conditions, chemically-modified mRNAs (produced by incorporation of the chemically-modified nucleotides 2-thiouridine and 5-methyl-cytidine in the in vitro transcription reaction) represent a novel technology for transfecting tissues and consequently expressing therapeutic proteins within the body (Kormann et al., 2011; Zangi et al., 2013). In the current proof of concept study, we reported the feasibility of using cmRNA technology as a potential therapeutic approach for expression of physiologically active proteins in intact and injured tendons. A self-established ex vivo transfection method enabled us to screen transfection efficacy of cmRNA in a variety of species (sheep, cattle, horses, hogs and rats), to optimise transfection conditions and to evaluate expression of several proteins (luciferase, $\beta$-galactosidase and BMP-7) in a cost and time efficient manner. Reporter protein expression was speciesindependent and expression levels were significantly higher when naked cmRNA was transfected, compared to cmRNA complexed with common lipid and polymer carriers. Furthermore, transgene expression could be further optimised by using naked mRNA dissolved in glucose-containing vehicle.

Results of our ex vivo studies were confirmed in 3 different in vivo models: intact rat common calcaneal tendons, injured rat common calcaneal tendons (dissected and surgically repaired) and collagenase-gel-induced tendon defect in sheep. Injection of cmRNA ${ }^{\mathrm{LUC}}$ into healthy rat tendons resulted in strong luciferase expression, peaking after $1 \mathrm{~d}$ and fading out within $7 \mathrm{~d}$ in a dose-dependent manner. These observations resembled the expression kinetics observed in our ex vivo studies.

Results of in vivo studies using reporter proteins prompted us to investigate the potential of cmRNA for expressing potentially therapeutic proteins. BMP-7 was selected as a potential therapeutic target, as it has been shown to play a crucial role in the healing process at the interface of tendons and bones (Forslund and Aspenberg, 1998). A rat model of surgically dissected common calcaneal tendons was selected to investigate the influence of hBMP-7-coding cmRNA in a pathological environment. Injection of $\mathrm{cmRNA}^{\mathrm{hBMP}-7}$ into injured tendons, resulted in increasing hBMP-7 levels compared to vehicle as early as $2 \mathrm{~d}$ after application and up to day 7. It needs to be mentoined that BMP-7 was also detected in vehicle treated tendons at all time points. Measured levels were constant during the entire study. Most likely, these background levels could be attributed to cross reactivity of antihBMP-7 antibody with rat BMP-7.

Catabolism of collagen type I and excessive replacement by collagen type III are considered to be important events in the early inflammatory phase (day 1 to day 7 post injury) of tendon injury (Loiselle et al., 2012; Sharma and Maffulli, 2005a). By time, collagen type III is either converted to full functional collagen type I (resulting in tissue regeneration) or to scar-like tissue, leading to loss of tensile strength and elasticity, compared to intact tendon tissue (Sharma and Maffulli, 2005b). In the present study, no differences were found with respect to the content of collagen type I in tendons, between animals treated with cmRNA ${ }^{\text {hBMP-7 }}$ or vehicle, at any of the examined time points. However, $7 \mathrm{~d}$ after injury and injection of the test item, significantly ( $p=0.03$ ) less collagen type III was found. Summarising, our findings indicated that $\mathrm{cmRNA}^{\mathrm{hBMP}-7}$ contributed to increased levels of hBMP-7 and reduced formation of collagen type III. Because only early time points were investigated, it might be too early to draw final conclusion whether cmRNA ${ }^{\text {hBMP-7 }}$ positively impacts physiological regeneration of tendons. Studies from other authors reported significant changes of collagen type I content and morphological changes towards regeneration as early as weeks or months post injury (Martinello et al., 2013). To finally answer the question, whether overexpression of hBMP-7 leads to increased content of collagen type I, further long term studies have to be conducted with examinations of the tendons at later time points.

In clinics, patients frequently report acute pain and/ or limitiation of the affected tendon in performing physiological movements. For example, partial rupture of the supraspinatus tendon leads to the inability to perform an abduction of more than $90^{\circ}$ of the affected extremity (Woodward and Best, 2000). In veterinary medicine, acute tendinitis of the SDFT represents a frequent cause of severe lameness in horses (Thorpe et al., 2010). However, before these clinical symptoms become noticeable, a long process of microtraumatic fibre disruption and subsequent inflammation is already present (Kannus, 1997). Patients frequently report unfavourable movements prior to the acute onset of the characteristic 
symptoms of an acute tendinopathy. Histopathologically healthy tendons differ significantly from tendons affected by actue tendinopathy. The latter is characterised by disintegration of the extracellular matrix, necrosis and presence of inflammatory cells, such as neutrophils and macrophages. Results of our ex vivo studies in healthy cadaver tendons showed reporter protein expression in a slim tube-like pattern along the entire tendon (Fig. 1C-H). To investigate cmRNA's capability of transfecting not only healthy, but also tendons resembling the characteristics of acute early tendinopathy, cmRNA was injected into healthy and collagenase-gel-injured DDFT of sheep. At day 1 after injection, ex vivo BLI confirmed luciferase expression in healthy and inflamed DDFT. Interestingly, injured tendons exhibited higher expression levels upon higher doses of cmRNA, whereas expression levels remained in a similar range, independent of the applied dose. These observations could possibly be explained by the altered composition of the extracellular matrix and presence of inflammatory cells in injured tendons. Disintegrated matrix might allow a wider spread of cmRNA throughout the tissue, as the limiting connective tissue sheats surrounding the tendon fibres are destroyed. This leads us to the assumption that therapeutic protein encoding cmRNA could possibly represent an interventional strategy for the transfection of acute tendon lesions.

These results promt us to believe that cmRNA might not only be a tool for expressing proteins in healthy tendons, but also in acute inflamed tendons, with the aim to attain tendon regeneration and reduce scar tissue formation. Our results with BMP-7, indicate that therapeutic proteins can indeed be expressed in injured tendons. To adress their therapeutic potential, future studies, investigating tendon healing process (later time points), need to be performed.

\section{Conclusion}

Naked cmRNAs in glucose-containing solutions were efficient in transfecting both healthy and injured tendons in a species-independent manner. The resulting protein was biologically active and localised to the site of injection. It is conceivable that cmRNAs can be utilised to encode any therapeutic protein of interest for the treatment of tendon disorders.

\section{Acknowledgments}

The authors gratefully acknowledge the assistance of Prof. Dr Walter Nathrath in histopathological assessment and the technical assistance of Marco Pegurri, Renzo Schumpf, Andrea Venturiere, as well as Viviane Trendelenburg, Sebastian Zoll and Lukas Adam.

\section{References}

Arguelles D, Carmona JU, Climent F, Munoz E, Prades M (2008) Autologous platelet concentrates as a treatment for musculoskeletal lesions in five horses. Vet Rec 162: 208-211.

Baird AE, Carter SD, Innes JF, Ollier WE, Short AD (2014) Genetic basis of cranial cruciate ligament rupture (CCLR) in dogs. Connect Tissue Res 55: 275-281.

Bosch G, Van Schie HT, De Groot MW, Cadby JA, Van De Lest CHA, Barneveld A, Van Weeren PR (2010) Effects of platelet-rich plasma on the quality of repair of mechanically induced core lesions in equine superficial digital flexor tendons: a placebo-controlled experimental study. J Orthop Res 28: 211-217.

Bray RC, Rangayyan RM, Frank CB (1996) Normal and healing ligament vascularity: a quantitative histological assessment in the adult rabbit medial collateral ligament. J Anat 188: 87-95.

Del Buono A, Battery L, Denaro V, Maccauro G, Maffulli N (2011) Tendinopathy and inflammation: some truths. Int J Immunopathol Pharmacol 24: 45-50.

Dai Q, Manfield L, Wang Y, Murrell G (2003) Adenovirus-mediated gene transfer to healing tendonenhanced efficiency. J Orthop Res 21: 604-609.

Evans C (2014) Using genes to facilitate the endogenous repair and regeneration of orthopaedic tissues. Int Orthop 38: 1761-1769.

Foland JW, Trotter GW, Powers BE, Wrigley RH, Smith FW (1992) Effect of sodium hyaluronate in collagenaseinduced superficial digital flexor tendonitis in horses. Am J Vet Res 53: 2371-2376.

Forslund C, Aspenberg P (1998) OP-1 has more effect than mechanical signals in the control of tissue differentiation in healing rat tendons. Acta Orthop Scand 69: 622-626.

Grotendorst GR (1988) growthfactors as regulators of wound repair. Int J Tissue React 10: 337-344.

Hart L (2011) Corticosteroid and other injections in the management of tendinopathies: a review. Clin J Sport Med 21: 540-541.

Herrmann SJ, Izadpanah K, Sudkamp NP, Strohm PC (2014) Tears of the rotator cuff. Causes-diagnosistreatment. Acta Chir Orthop Traumatol Cech 81: 256-266.

Hogan MV, Bagayoko N, James R, Starnes T, Katz A, Chhabra AB (2011) Tissue engineering solutions for tendon repair. J Am Acad Orthop Surg 19: 134-142.

Ippolito E, Postacchini F, Ricciardi-Pollini PT (1975) Biochemical variations in the matrix of human tendons in relation to age and pathological conditions. Ital J Orthop Traumatol 1: 133-139.

James R, Kesturu G, Balian G, Chhabra AB (2008) Tendon: biology, biomechanics, repair, growth factors, and evolving treatment options. J Hand Surg Am 33: 102-112.

Järvinen M, Józsa L, Kannus P, Järvinen TL, Kvist M, Leadbetter W (1997) Histopathological findings in chronic tendon disorders. Scand J Med Sci Sports 7: 86-95.

Järvinen TAH, Kannus P, Maffulli N, Khan KM (2005) Achilles tendon disorders: etiology and epidemiology. Foot Ankle Clin 10: 255-66.

Kannus P (1997) Etiology and pathophysiology of chronic tendon disorders in sports. Scand J Med Sci Sports 7: 78-85.

Kormann MSD, Hasenpusch G, Aneja MK, Nica G, Flemmer AW, Herber-jonat S, Huppmann M, Mays LE, 
Illenyi M, Schams A, Griese M, Bittmann I, Handgretinger R, Hartl D, Rosenecker J, Rudolph C (2011) Expression of therapeutic proteins after delivery of chemically modified mRNA in mice. Nat Biotechnol 29: 154-157.

Kvist M (1994) Achilles tendon injuries in athletes. Sports Med 18: 173-201.

Liu C-F, Aschbacher-Smith L, Barthelery NJ, Dyment N, Butler D, Wylie C (2011) What we should know before using tissue engineering techniques to repair injured tendons: a developmental biology perspective. Tissue Eng Part B Rev 17: 165-176.

Loiselle AE, Frisch BJ, Wolenski M, Jacobson JA, Calvi LM, Schwarz EM, Awad HA, O'Keefe RJ (2012) Bone marrow-derived matrix metalloproteinase- 9 is associated with fibrous adhesion formation after murine flexor tendon injury. PLoS One 7: e40602.

Lou J, Tu Y, Burns M, Silva MJ, Manske P (2001) BMP-12 gene transfer augmentation of lacerated tendon repair. J Orthop Res 19: 1199-1202.

Maffulli N, Longo UG, Denaro V (2010) Novel approaches for the management of tendinopathy. J Bone Joint Surg Am 92: 2604-2613.

Magnan B, Bondi M, Pierantoni S, Samaila E (2014) The pathogenesis of Achilles tendinopathy: a systematic review. Foot Ankle Surg 20: 154-159.

Majewski M, Betz O, Ochsner PE, Liu F, Porter RM, Evans CH (2008) Ex vivo adenoviral transfer of bone morphogenetic protein 12 (BMP-12) cDNA improves Achilles tendon healing in a rat model. Gene Ther 15: 1139-1146.

Martinello T, Bronzini I, Perazzi A, Testoni S, De Benedictis GM, Negro A, Caporale G, Mascarello F, Iacopetti I, Patruno M (2013) Effects of in vivo applications of peripheral blood-derived mesenchymal stromal cells (PB-MSCs) and platlet-rich plasma (PRP) on experimentally injured deep digital flexor tendons of sheep. J Orthop Res 31: 306-314.

Mast BA (1997) Healing in other tissues. Surg Clin North 77: 529-547.

Millar NL, Gilchrist DS, Akbar M, Reilly JH, Kerr SC, Campbell AL, Murrell G a C, Liew FY, KurowskaStolarska M, McInnes IB (2015) MicroRNA29a regulates IL-33-mediated tissue remodelling in tendon disease. Nat Commun 6: 6774.

Molloy T, Wang Y, Murrell GAC (2003) The roles of growth factors in tendon and ligament healing. Sport Med 33: 381-394.

Moraes JRE, Facco GG, Moraes FR, Engracia Filho JR, Miyazato LG, Beretta DC (2009) Effects of glycosaminoglycan polysulphate on the organisation of collagen fibres in experimentally induced tendonitis in horses. Vet Rec 165: 203-205.

Muneta T, Koga H, Ju YJ, Mochizuki T, Sekiya I (2012) Hyaluronan injection therapy for athletic patients with patellar tendinopathy. J Orthop Sc 17: 425-431.

Muto T, Kokubu T, Mifune Y, Inui A, Harada Y, Takase F, Kuroda R, Kurosaka M (2014) Temporary inductions of matrix metalloprotease-3 (MMP-3) expression and cell apoptosis are associated with tendon degeneration or rupture after corticosteroid injection. J Orthop Res 32: 1297-1304.

Nakamura N, Shino K, Natsuume T, Horibe S, Matsumoto N, Kaneda Y, Ochi T (1998) Early biological effect of in vivo gene transfer of platelet-derived growth factor (PDGF)-B into healing patellar ligament. Gene Ther 5: 1165-1170.

Patterson-Kane JC, Rich T (2014) Achilles tendon injuries in elite athletes: lessons in pathophysiology from their equine counterparts. ILAR J 55: 86-99.

Perkins NR, Reid SWJ, Morris RS (2005) Risk factors for injury to the superficial digital flexor tendon and suspensory apparatus in Thoroughbred racehorses in New Zealand. N Z Vet J 53: 184-192.

Renzi S, Riccò S, Dotti S, Sesso L, Grolli S, Cornali M, Carlin S, Patruno M, Cinotti S, Ferrari M (2013) Autologous bone marrow mesenchymal stromal cells for regeneration of injured equine ligaments and tendons: a clinical report. Res Vet Sc 95: 272-277.

Seeliger C, Falldorf K, Sachtleben J, Griensven M Van (2014) Low-frequency pulsed electromagnetic fields significantly improve time of closure and proliferation of human tendon fibroblasts. Eur J Med Res 19: 37.

Shah V, Bendele A, Dines JS, Kestler HK, Hollinger JO, Chahine NO, Hee CK (2013) Dose-response effect of an intra-tendon application of recombinant human plateletderived growth factor-BB (rhPDGF-BB) in a rat Achilles tendinopathy model. J Orthop Res 31: 413-420.

Sharma P, Maffulli N (2005a) Basic biology of tendon injury and healing. Surg 3: 309-316.

Sharma P, Maffulli N (2005b) The future: Rehabilitation, gene therapy, optimization of healing. Foot Ankle Clin 10: 383-397.

Smith RKW (2008) Mesenchymal stem cell therapy for equine tendinopathy. Disabil Rehabil 30: 1752-1758.

Thorpe CT, Clegg PD, Birch HL (2010) A review of tendon injury: why is the equine superficial digital flexor tendon most at risk?. Equine Vet 42: 174-180.

Tong H, Shi Q, Fernandes JC, Liu L, Dai K, Zhang $X$ (2009) Progress and prospects of chitosan and its derivatives as non-viral gene vectors in gene therapy. Curr Gene Ther 9: 495-502.

Watts AE, Nixon AJ, Yeager AE, Mohammed HO (2012) A collagenase gel/physical defect model for controlled induction of superficial digital flexor tendonitis. Equine Vet J 44: 576-586.

Witte TH, Yeager AE, Nixon AJ (2011) Intralesional injection of insulin-like growth factor-I for treatment of superficial digital flexor tendonitis in Thoroughbred racehorses: 40 cases (2000-2004). J Am Vet Med Assoc 239: 992-997.

Woodward TW, Best TM (2000) The painful shoulder: part I. Clinical evaluation. Am Fam Physician 61: 30793088.

Zangi L, Lui KO, von Gise A, Ma Q, Ebina W, Ptaszek LM, Später D, Xu H, Tabebordbar M, Gorbatov R, Sena B, Nahrendorf M, Briscoe DM, Li RA, Wagers AJ, Rossi DJ, $\mathrm{Pu}$ WT, Chien KR (2013) Modified mRNA directs the fate of heart progenitor cells and induces vascular regeneration after myocardial infarction. Nat Biotechnol 31: 898-907. 


\section{Discussion with Reviewers}

Kasia Whysall: How do you envisage a clinical application of the method described in terms of tendinopathies?

Authors: Therapeutic mRNAs could be used during surgery to positively influence the process of re-adaption (similar to the common calcaneal disruption model in rats). This may be useful in cases of partial or complete disruption of one of the rotator cuff tendons. Moreover, we foresee potential applications in the field of equine veterinary medicine. Many horses suffer from superficial digital flexor tendon impairments. In such cases, therapeutic mRNAs could be directly injected into the tendon defect using ultrasound guidance, as described in the collagenase-gel-induced tendinitis in sheep.

Gundula Schulze-Tanzil: What about the stability of cmRNA against endogen RNAses and antigenicity of this xenogenic RNA?

Authors: Though in vivo naked cmRNA are degraded upon injection into tendons, we believe that stability might be strong enough for them to keep their biological functionality. However, studies must be done to examine exactly this issue. With respect to antigenicity of the xenogenic RNAs, we cannot provide any information as we have not examined this issue.

Gundula Schulze-Tanzil: What is the advantage of cmRNA transfection compared to simple injection of BMP-7 [Ozeki et al., (2013)]?

Authors: Recombinant growth factors are characterised by limited half-lives. In our present study, we have shown that proteins can be expressed for a period up to $3 \mathrm{~d}$. Moreover, mRNAs can be used to express every protein desired. Hence, we see applications utilising the expression of transcription factors or long non-coding RNAs in order to influence cellular function.

Gundula Schulze-Tanzil: When testing the effect of different agents on cmRNA transfection efficacy, how about mediators increasing the blood flow in tendons? I think this could not be tested in explants but rather in an appropriate in vivo model. Also, in vivo, the blood flow might be increased by biomechanical stimulation.
Authors: We fully agree. This might be an interesting topic for future investigations. Morphological alterations of the tissue, but also changes in blood flow might influence transfection efficacy of mRNAs. In our present work, we observed that expression seems to be more localised to fibre bundles in intact tendons and tending to spread more intensively in inflamed tendons.

Gundula Schulze-Tanzil: The effects expected by BMP7 in tendons are not thoroughly discussed. After injection of BMP-7 in a rat model, Ozeki et al., (2013) reported fibrocartilaginous transdifferentiation of Achilles tendon fibroblast into fibrochondrocytes. Perhaps markers of cartilage expression, such as type II collagen (or aggrecan and Sox9), should be included in the analysis of the healing tendons, to exclude unwanted fibrocartilage formation.

Authors: We did not performed this analysis in the present work because we monitored the expression of hBMP-7 only for a short period (one week). This is long enough to show that there is protein expression, but not long enough to observe effects like ectopic bone formation. Bone formation upon application of BMP-7 could be useful in the re-adaption process of lacerated tendons. However, it might as well be possible that tissue environment influences which particular effect (bone formation or not) could be induced through BMP-7. All these are questions for very interesting future studies.

\section{Additional Reference}

Ozeki N, Muneta T, Koga H, Katagiri H, Otabe K, Okuno M, Tsuji K, Kobayashi E, Matsumoto K, Saito H, Saito T, Sekiya I (2013) Transplantation of Achilles tendon treated with bone morphogenetic protein 7 promotes meniscus regeneration in a rat model of massive meniscal defect. Arthritis Rheum 65: 2876-2886

Editor's note: The Scientific Editor responsible for this paper was Juerg Gasser. 